\title{
DEVELOPMENTS OF LONG-PULSE KLYSTRON MODULATOR FOR KEK SUPER-CONDUCTING RF TEST FACILITY
}

\author{
Hitoshi Mori, Katsuhiko Furuya, NICHICON (KUSATSU) Corporation, Shiga, Japan
}

Mitsuo Akemoto, Shigeki Fukuda, Hiroyuki Honma, Hiromitsu Nakajima, Tetsuo Shidara, KEK, Ibaraki, Japan

\section{Abstract}

NICHICON (KUSATSU) CORPORATION and KEK have developed a novel long-pulse klystron modulator for both of single-beam tube $\left(136 \mathrm{kVp}^{*} 100 \mathrm{~A}\right)$ and multi-beam tube $(120 \mathrm{kVp} * 140 \mathrm{~A})$.

The main features are; - crowbar-less system with optimized IGBT snubber circuit, - compact and highly reliable Self-Healing capacitors, - HV \& LV twin pulse transformers of laminated steel core for reduced tank volume.

\section{INTRODUCTION}

KEK had constructed first Long Pulse Klystron modulator for ILC SC (super-conducting) RF cavity, and now RF experiments are performed. [1] The authors have developed the second modulator, newly designed, aiming economical efficiency for future mass production. Figure 1 shows the side view, and figure 2 shows typical waveform of primary voltage and current.

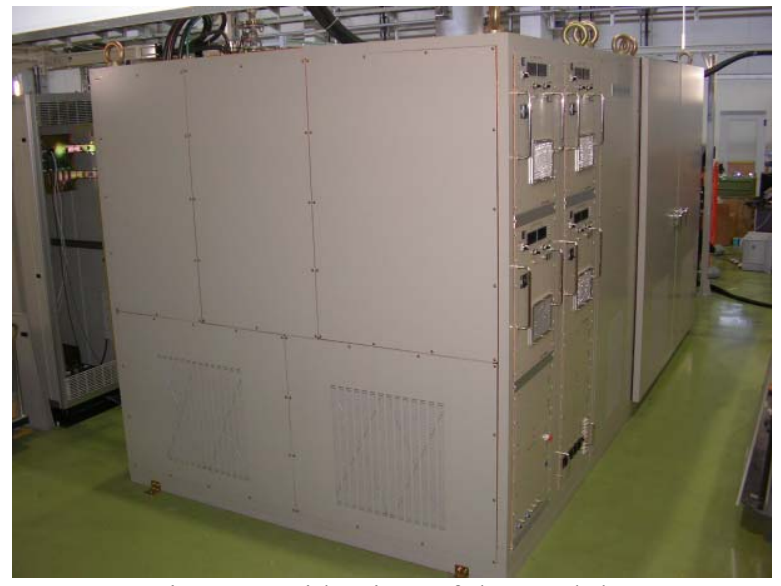

Figure 1: Side view of the modulator.

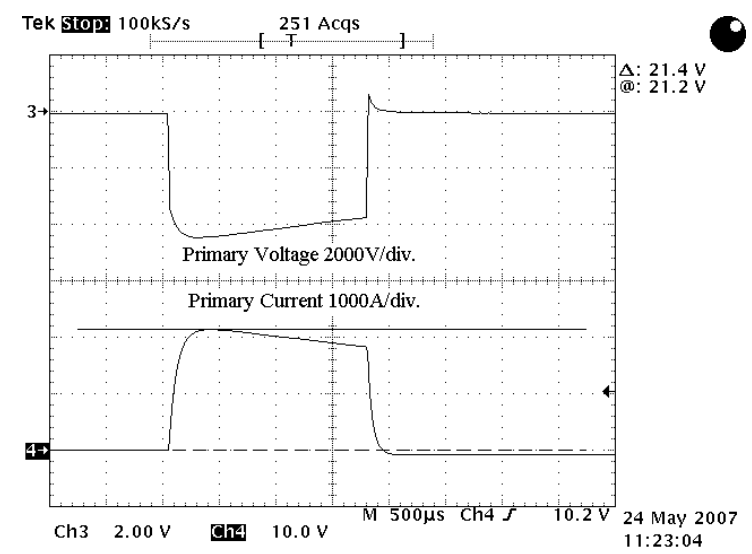

Figure 2: Typical Output Waveform.

\section{CROWBAR-LESS SYSTEM BY HIGHLY RELIABLE IGBT SWITCH}

The modulator main switch is composed of IGBT switch units; those are stacked into one row of 20 elements in series and 4 rows in parallel. Similar IGBT switch system has experienced long-term performance in nuclear fusion experiments in Japan. Figure3 and Figure4 show the both side views of the IGBT switch plate, where 2 IGBT elements in series are installed.

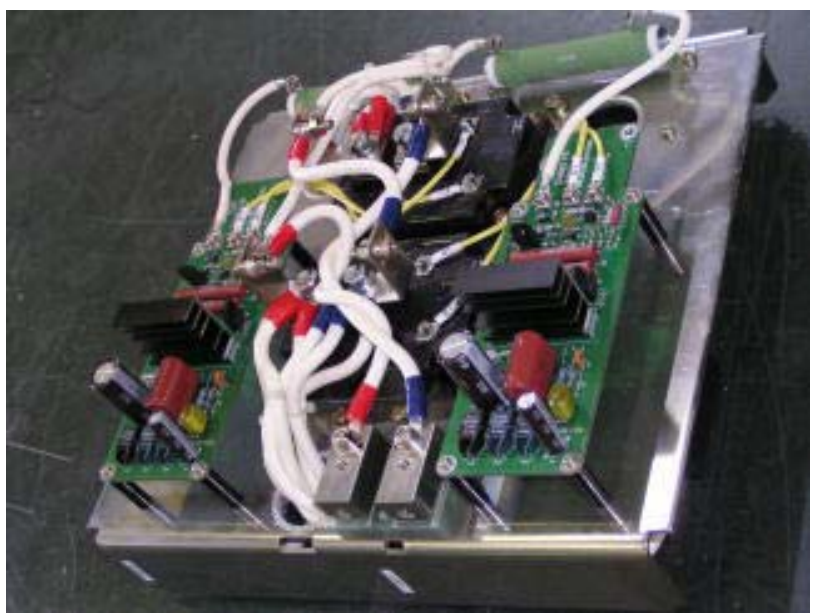

Figure 3: IGBT element side view of IGBT switch plate.

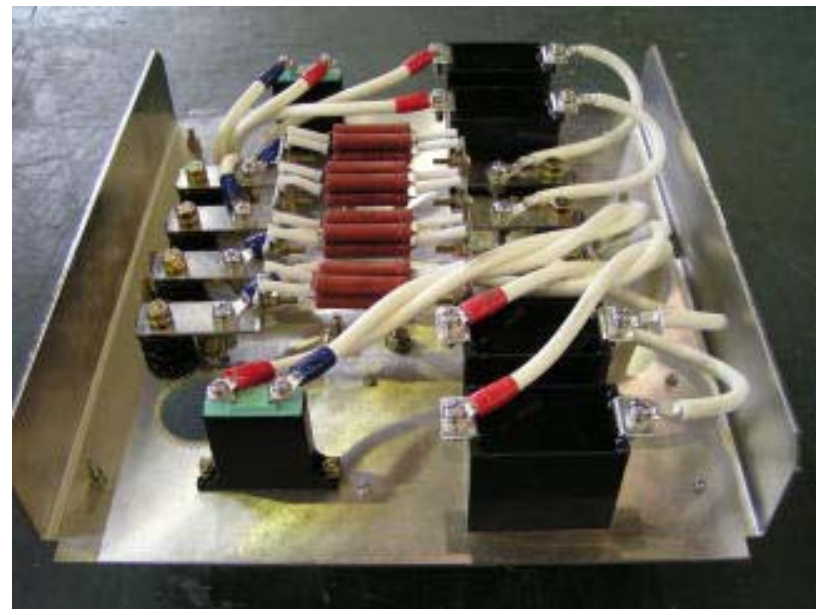

Figure 4: snubber side view of IGBT switch plate.

\section{Optimal Snubber Design}

When the IGBTs are turned off; a spike voltage appears across the collector and the emitter electrodes. If the spike voltage is not appropriately treated, it rises beyond the IGBT's maximum rating voltage, then it damages to the IGBTs. 
The authors selected specific values of the snubber resistance and capacitance in the following manner, -At first, the main current is commutated from the IGBT to the snubber. The voltage is approximately the product of the current and the snubber resistance. The resistance value was determined so that the spike voltage would not rise beyond about half of the maximum rating voltage of the IGBT elements.

After the commutation, stored energy in residual inductance of the primary circuit is absorbed into the snubber resistors and capacitors. Therefore we determined the capacitance value using numerical simulation. Here, the leakage inductance of output pulse transformer is short cut by tail clipper circuit.

As the result, the optimized snubber design allows moderate value of residual inductance in the primary discharge loop, approximately 5 micro $\mathrm{H}$.

\section{IGBT Driver Power Feeding}

The power into the IGBT driver electronics is fed from the main circuit; while the IGBTs are OFF the power inlet part of the electronics, composed of resistors and constant current circuit, functions as a voltage balancer.

\section{Semi-Double Control and Fault Detection}

The IGBT driver electronics receives two optical control signals to turn on/off the IGBT elements, and the transmitting circuits are composed as semi-double configuration; two logic circuits and driver circuits, and single power supply and timing control.

One optical signal is transmitted from each IGBT driver electronics, while the power is fed. The control logic detects failure if one of the signals turned off; it indicates the failure of the IGBT element or the driver electronics.

\section{COMPACT AND HIGHLY RELIABLE SELF-HEALING CAPACITORS}

NICHICON supplies various types of customized capacitors especially for high voltage and high current discharge application. The current waveform and repetition rate for the Klystron modulator is not so severe, that Self-Healing type capacitors made of metalized plastic film are applicable, with smaller size and higher energy density. The specification is shown in table 1 .

Table 1: Specification of main capacitor

\begin{tabular}{|l|l|r|}
\hline Specification & Unit & Value \\
\hline Capacitance & micro F & 440 \\
\hline Number of Capacitor units & \multicolumn{1}{|c|}{-} & 4 \\
\hline Rated dc Voltage & $\mathrm{kV}$ & 11 \\
\hline Energy Storage & $\mathrm{kJ}$ & 26.6 \\
\hline Weight & $\mathrm{kg}$ & 140 \\
\hline Volume/100kJ & $\mathrm{m}^{\wedge} 3$ & 0.415 \\
\hline Weight/kJ & $\mathrm{kg}$ & 5.3 \\
\hline Lifetime & hour & 90000 \\
\hline
\end{tabular}

\section{MASS-PRODUCTION ORIENTED TRANSFORMER DESIGN}

In order to minimize the tank volume, the step-up pulse-transformer is divided into two transformers; one is for full withstanding voltage and the other is for half.

Because the size of wound magnetic steel core is limited by winding machine, the authors has preferred laminated core, suitable to mass-production. The transparent diagram is shown in Figure5.
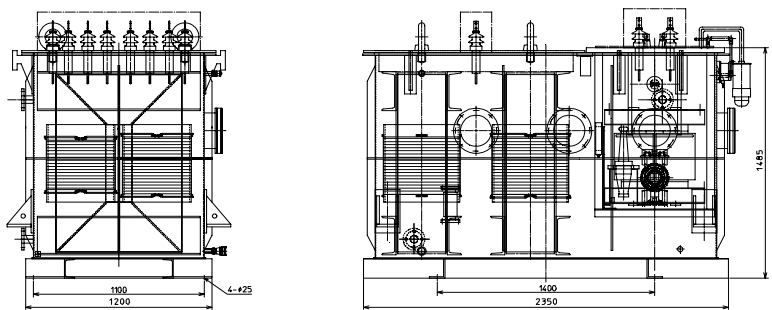

Figure 5: Transparent diagram of the pulse transformer.

\section{SUMMARY}

The second klystron modulator for SCRF KEK has shown its economical efficiency. KEK plans the aging and high power tests of multi-beam klystrons under development.

\section{REFERENCE}

[1] S. Fukuda et al., "Status of RF Sources in Super-Conducting RF Test Facility (STF) at KEK", Proc. L INAC06, Knoxville, TN, USA, pp.613-615, 2006. 